\section{O emprego da locução [meio + que]: um enfoque funcionalista no vernáculo conquistense}

The use of the expression [meio + que]: a functional approach in the vernacule from Vitória da Conquista

Gilsileide Cristina Barros LIMA (UESB) gilbarroslima@gmail.com Valéria Viana SOUSA (UESB) valeriavianasousa@gmail.com Jorge Augusto Alves da SILVA (UESB) adavgvstvm@gmail.com
LIMA, Gilsileide Cristina Barros;

SOUSA, Valéria Viana; SILVA, Jorge

Augusto Alves da. O emprego

da locução [meio + que]: um enfoque funcionalista no vernáculo conquistense. Entrepalavras, Fortaleza, v. 7, p. 57-75, jan./jun. 2017.

Resumo: Neste trabalho, analisamos, segundo os princípios do Funcionalismo norte-americano e da gramaticalização, a construção [meio + que] em entrevistas extraídas do Português Culto de Vitória da Conquista (Corpus PCVC). Nosso objetivo foi identificar as propriedades morfossintáticas, semânticase discursivas dessa locução que, invariavelmente desconhecida nos registros formais de uso da língua, assume valores discursivos próprios e tende a se fixar no sistema linguístico.

Palavras-chave: Funcionalismo. Gramaticalização. [Meio + que]. 
v. $7(1)$

57-75

jan/jun

2017

Abstract: In this work, we analyze, according to the principles of North American Functionalism and grammaticalization, the construction [meio + que] in interviews extracted from the Cult Portuguese of Vitória da Conquista (CPVC Corpus). Our objective was to identify the morphosyntactic, semantic and discursive properties of this locution that, invariably unknown in the formal records of the language use, assumes its own discursive values and tends to settle in the linguistic system.

Keywords: Functionalism. Grammaticalization. [Meio + que].

\section{Introdução}

Este artigo é parte de uma pesquisa realizada durante o mestrado em Linguística (LIMA, 2016), quando analisamos os usos e a trajetória de gramaticalização de meio. Naquela ocasião, com base em dicionários de diferentes períodos, observamos que, em época remota, esse item linguístico já toma para si diversos sentidos e classificações gramaticais, com uma propensão para qualificar ou estender o sentido do(s) termo(s) ao(s) qual(is) se associa.

Entre os inúmeros deslizamentos funcionais de meio, está [meio + que], uma expressão corrente, que sinaliza uma avaliação caracterizada pela relação do falante com o conteúdo do seu enunciado. Nosso objetivo é, portanto, à luz das proposições do Funcionalismo norte-americano e da gramaticalização, analisar as características linguísticas, morfológicas, sintáticas e semânticas da estrutura [meio + que], nos dados do Português Culto de Vitória da Conquista (Corpus PCVC $)^{1}$, para compreendermos os contextos que favorecem a mudança linguística e originam [meio + que $]$.

Organizamos este texto da seguinte forma: Na seção 2, "Fundamentação teórica", tratamos do Funcionalismo norte-americano, teoria segundo a qual os elementos de uma língua são analisados e descritos do ponto de vista de sua função no ato da comunicação. Seguimos com a gramaticalização, processo pelo qual as palavras se

\footnotetext{
${ }^{1}$ Esse Corpus integra o trabalho do Grupo de Estudos em Linguística Histórica e em Sociofuncionalismo - UESB/CNPq. Nesse grupo, desenvolve-se o Projeto "Estudo de fenômenos linguísticos na perspectiva (sócio) funcionalista, com base na descrição e análise da comunidade de fala de Vitória da Conquista", com cadastro no Certificado de apresentação para Apreciação Ética (CAAE), número 34221214.9.0000.00552, e de responsabilidade da pesquisadora Prof. ${ }^{a}$ Dr. ${ }^{a}$ Valéria Viana Sousa, também líder do Grupo de Pesquisa em Linguística Histórica e em Sociofuncionalismo - UESB/CNPq. Analisamos dados de entrevistas da modalidade oral do Português Culto de Vitória da Conquista (Corpus PCVC). Foram entrevistados 12 informantes, abrangendo as seguintes variáveis sociais: seis do sexo feminino e seis do sexo masculino. Quanto à faixa etária, quatro dos informantes têm entre 15 e 34 anos, quatro entre 35 e 49 anos e quatro mais de 50 anos.
} 
movimentam no curso da evolução de uma língua. Encerramos o apoio teórico com os mecanismos que ajudam a explicar a mudança linguística: a metáfora e a metonímia. Na seção 3, "Os sentidos cambiantes de meio", verificamos, de maneira breve, a etimologia e as significações desse elemento em dicionários da Língua Portuguesa de diferentes épocas. Na seção 4 "As diversas relações do que na Língua Portuguesa", observamos a etimologia e de que modo alguns autores apreendem a combinação dessa partícula com outros itens da Língua Portuguesa. Na seção 5, "A locução [meio + que]: encadeamento e propriedades", descrevemos as características dessa expressão em ocorrências do Corpus PCVC. A seção 6, "Considerações finais", resume a discussão ora realizada.

\section{Fundamentação teórica}

\section{Funcionalismo}

Na perspectiva do Funcionalismo norte-americano, a língua está sempre em transformação, de modo que os itens e construções gramaticais não são estáveis. Consoante essa maneira de pensar, a sintaxe é uma estrutura em constante mutação e se estabelece em razão das estratégias de organização da informação dos falantes no momento da interação discursiva. Para compreendê-la, é preciso, antes, "estudar a língua em uso, em seus contextos discursivos específicos, pois é nesse espaço que a gramática é constituída" (MARTELOTTA, 2003, p. 24) e onde está a motivação para os fatos da língua.

Lima-Hernandes (2011, p. 23) revela "não conceber a existência de uma sintaxe autônoma". A pesquisadora sustenta-se no argumento de que os componentes semântico e sintático não são autônomos em relação ao componente pragmático. Do ponto de vista funcional, a língua "é um sistema semântico e, como tal, manifesta a produção de sentidos por meio de enunciados linguísticos, estruturados a partir de uma organização específica de itens gramaticais e lexicais" (LIMAHERNANDES, 2011, p. 23).

Consideremos os trechos abaixo, extraídos de entrevistas do Corpus PCVC:

(1) Volta e meia acontece alguma coisa... (R.F.V.).

(2) [...] de hoje que é o que todo mundo curte a massa curte é algo assim meio degradante [...] (C.B.S.). 
v. 7 (1)

$57-75$

jan/jun

2017

(3) [...] que ela tá sempre necessitando de algo mais que não... está no meio material, (C.S.M.N.).

(4) [...] a cidade fica meio a desejá (L.M.R.J.).

(5) $[\ldots]$ era uma pessoa meio de gente que num existe mais, sabe? (A.I.R.M.)

(6) $[\ldots]$ eu tinha um sentimento meio que de proteção porque ela era muito tímida (D.F.P.).

Nos exemplos, a palavra meio assume funções e categorias gramaticais diversas. Ocorrências como (1), (2) e (3) são acolhidas pela norma gramatical tradicional. Outras, como (4), (5) e (6), fazem parte do sistema funcional da língua portuguesa e não têm o seu uso prescrito em gramáticas normativas. Todas "sinalizam a dinamicidade da interação linguística e as necessidades pragmáticas que impelem o falante a buscar adequada codificação sintática" (LIMA-HERNANDES, 2011, p. 25).

Em conformidade, ou não, com a gramática normativa, as formas linguísticas originam-se com base em princípios comunicativos e devem ser descritas e analisadas do ponto de vista de sua função no ato da comunicação.

O surgimento de funções para formas já existentes e de formas para funções também existentes consiste no que chamamos gramaticalização. Os traços desse processo seguem delineados na próxima subseção.

\section{Gramaticalização}

Originada no seio do Funcionalismo, os estudos sobre a gramaticalização centram-se no fato de as línguas serem essencialmente dinâmicas, a cada momento surgem construções, outras desaparecem, outras ainda passam a ser empregadas com funções distintas daquelas que conhecemos.

Embora não haja consenso sobre o conceito de gramaticalização, um dos mais tradicionais é "processo em que itens lexicais assumem funções gramaticais e, gramaticalizados, exercem funções mais gramaticalizadas" (NEVES, 1997, p. 115).

Outros teóricos acolhem a ideia de que a gramaticalização consiste na passagem de um elemento lexical à unidade gramatical ou de um item gramatical a mais gramatical ainda. É o que sustenta Neves (1997, p. 120), a qual declara: 
Heine et alii. (1991) abrigam sob o termo gramaticalização tanto o percurso de um morfema do estatuto lexical para o gramatical, como o percurso do estatuto menos gramatical para o mais gramatical.

Também, conforme a linguista:

Ainda Hopper (1991, p. 17-35), rejeitando a noção de uma gramática estável, diz que todas as partes da gramática estão sempre sofrendo mudanças, e, por isso, os fenômenos gramaticais em geral podem ser pensados como envolvidos na gramaticalização (NEVES, 1997, p. 121).

Com base nesse pensamento, o argumento de que não existe uma gramática pronta e acabada, mas, sim, uma gramática em constante evolução, se fortalece.

Castilho (1997, p. 32) entende a Gramaticalização, primeiro, como "a codificação de categorias cognitivas em formas linguísticas, aí incluídas a percepção do mundo pelas diferentes culturas, o processamento da informação etc.". Em seguida, como um processo de constituição da gramática ou um conjunto de processos por que passa uma palavra, durante os quais

(i) ela ganha novas propriedades sintáticas, morfológicas, fonológicas e semânticas; (ii) transforma-se numa forma presa; (iii) e pode até mesmo desaparecer, como consequência de uma cristalização extrema (CASTILHO, 2012, p. 138).

O linguista argumenta que, ao compor uma gramática, as comunidades elegem uma representação linguística para as categorias cognitivas, alterando-as no decorrer do tempo. Essas categorias, no entanto, são estáveis, o que muda é a sua representação gramatical, semântica e discursiva (CASTILHO, 2012, p. 138).

Conforme expusemos, no processo de gramaticalização, atua um princípio que faz surgir funções para formas já existentes e formas para funções já existentes. Esse princípio norteia a ideia de que "conceitos concretos são mobilizados para o entendimento, explanação e descrição de um fenômeno menos concreto" (GONÇALVES et al., 2007, p. 42). Tal movimento respalda a metáfora e a metonímia, mecanismos que ajudam a explicar a mudança linguística, dos quais trataremos na próxima subseção. 
v. $7(1)$

57-75

jan/jun

2017

Metáfora e Metonímia

Ametáfora ocorrepor meio daanalogiae consiste "na transferência conceptual, que aproxima domínios cognitivos diferentes". A analogia, no entendimento de Bybee (2010), baseia-se na transferência de um domínio conceptual para outro por meio de uma associação estabelecida entre esses domínios. Bybee (2010, p. 4) assinala: "dada a especificidade das construções e a forma como elas são construídas por meio da experiência com a linguagem, a probabilidade e a aceitabilidade de um novo item é gradual e baseada em seus antigos usos".

A metonímia, mediante a reanálise, compõe a "motivação pragmática, que envolve a reinterpretação induzida pelo contexto" (GONÇALVES et al., 2007, p. 42), em função da proximidade sintática de formas linguísticas. Complementar da metáfora, a metonímia representa uma "associação conceptual fundamentada no mundo discursivo, ou uma transferência semântica licenciada por contiguidade", conforme apontam Gonçalves et al. (2007, p. 47). Decorre da reanálise, em que acontece a aproximação de significações, "uma palavra em uma frase na qual uma ideia, de alguma maneira ligada ao significado da palavra em questão, é passível de formar um elemento do contexto".

Para manifestar-se, a metonímia depende do encadeamento sintático, ou chunking, recurso que, ao lado da analogia, aparece na lista de domínios ${ }^{2}$ gerais envolvidos na configuração linguística arrolada por Bybee (2010). Intrínseco ao ser humano e baseado na organização da memória, o encadeamento funda-se na relação fixa de palavras na formação de estruturas linguísticas. A relação fortalece-se à medida que essas palavras são aplicadas na cadeia sintagmática.

Sobre a ativação de tal processo, Cunha et al. (2013, p. 32) declaram: embora extensa, uma cadeia de palavras pode ser produzida e processada mais facilmente se essas palavras podem ser acessadas em conjunto, devido à frequência de uso.

Pautados nessas considerações, na próxima seção, verificaremos a configuração de meio na língua portuguesa em diferentes épocas.

\footnotetext{
${ }^{2}$ Processos cognitivos de domínio geral envolvidos na configuração linguística: analogy (analogia), chunking (encadeamento), rich memory storage (estoque de memória enriquecida), cross-modal association (associação transmodal) e categorization (categorização) (BYBEE, 2010).
} 


\section{Os sentidos cambiantes de meio}

Na versão de Bueno (1974), a palavra meio vem do Latim médium, e é o primeiro elemento dos compostos eruditos com a ideia de menor, do gr. meiôn, menor, cuja forma deve ser mio.

Em Bluteau (1728, s.v.)3, do original: "expediente, razão, artifício, invenção para conseguir alguma coisa" (7), esse elemento se apropria de significados subsidiários mais concretos "lugar, ou parte entre os extremos" (8), "metade de alguma coisa" (9) e parte para outros mais vagos e imprecisos "algo", "um pouco", "um tanto", "não totalmente" (10).

(7) Substantivo. Qualquer expediente, induftria, razão, artificio, invenção que jerve para conjeguir algũa couja. Ratio, onis. Fem. Via, viae. Fem. Cic. (BLUTEAU, 1728, p. 473).

(8) No meyo. Entre. No meyo dos mais. Inter ceteros. Cic. (BLUTEAU, 1728, p. 475).

(9) Adjetivo. Parar o vomito he meya Jaude alcançada. Pars fanitatis est, vomitum esse supprefsum. Cels (BLUTEAU, 1728, p. 475).

(10) Meyo (quando je lhe segue hum adjectivo) Meyo comido, ou ruído (BLUTEAU, 1728, p. 475).

Da classe dos substantivos e adjetivos - séculos XVIII e XIX meio passa a compor - a partir do século XX - o grupo das locuções (11), advérbios (12) e numerais (13).

(11) Neste em meio - neste comenos, ínterim, neste entretanto. Neste em meio chegou Custódia (Camilo). (JUCÁ FILHO, 1963, p. 417).

(12) Anda meio doente. (FERREIRA, 2009, p. 1304).

(13) Um meio: meia laranja; meio quilômetro; meio quilo. (FERREIRA, 2009, p. 1304).

Desde outrora, meio também demonstra uma grande tendência para formar locuções de uso inovador. Já em Bluteau (1728), surgem de

3 O Vocabulário Portuguez e Latino (1712-1728), de Raphael Bluteau, é o primeiro dicionário da Língua Portuguesa. A digitalização de seus dez volumes integra a construção da biblioteca digital da Brasiliana USP. Trata-se de um projeto da Reitoria da Universidade de São Paulo desenvolvido em parceria pelo IEB e Biblioteca Guita e José Mindlin. Disponível em: http://www.brasiliana.usp.br 
v. $7(1)$

57-75

jan/jun

2017

meyo a meyo e de por meyo. Mesmo sem uma definição precisa, ambas parecem querer incorporar-se ao português. Vejamos:

Meyo. Outros modos de falar, em que ufamos defta palavra. (Ou tirão o chapeo de meyo a meyo, ou o pendurão pela ponta do cairel, como em tenda de Sirgueiro. Lobo, Corte na Aldca 339.) (Não fazendo cajo de rejpeitos próprios, quando eftava de por meyo o zelo da juftiça. Marinho, Apologer. Difcurt. 129.) (BLUTEAU, 1728, p. 476) [grifos nossos].

Mais de meio século depois, essas duas locuções reaparecem em Silva (1789)4, agora com outra representação escrita, e perfeitamente integradas à língua. A primeira, de meio a meio, vem revestida de uma significação bastante precisa: "De meio a meio; i. é, inteiramente. Lobo. v.g. "enganarão-se de meio a meio". foi encalhar na restinga de meio a meio, em dia claro, e sereno. Couto" (SILVA, 1789, p. 283). A segunda, de por meyo, com transformações na estrutura gramatical e uma significação mais discursiva: "Metter-se, ou entrar de per meio para compor desavindos: ser medianeiro" (SILVA, 1789, p. 283).

Nesse intenso movimento, em que se apodera de duas grafias ${ }^{5}$, de diversas categorias gramaticais, funções e valores semânticos, meio prova que os elementos linguísticos podem ganhar propriedades sintáticas, morfológicas, fonológicas, semânticas e, com o passar do tempo, desaparecer, "consequência de uma cristalização extrema" (CASTILHO, 2012, p. 138), como ocorre com de meyo a meyo e de por meyo.

Tal como meio, a partícula que não é coadjuvante e exerce papel importante na estrutura meio que. Por essa razão, julgamos necessário analisar também as suas propriedades na Língua Portuguesa, para que possamos melhor compreender a formação dessa estrutura. Passemos a essa parte.

\section{As diversas relações do que na Língua Portuguesa}

Etimologicamente, o então pronome qui podia exercer em Latim a função de pronome relativo e interrogativo e referia-se a nomes do gênero masculino, cujo correspondente feminino era quae. Posteriormente, o qui assumiu a designação dos dois gêneros e suplantou o feminino quae. Mais tarde, ele próprio desapareceu. O acusativo quem se fundiu com o neutro quid e formou o que.

\footnotetext{
${ }^{4}$ A digitalização dessa obra também integra a construção da biblioteca digital da Brasiliana USP. Disponível em: <http://www.brasiliana.usp.br>.

${ }^{5}$ No século XVIII, escrevia-se meyo.
} 
Com base em Francisco da Silveira Bueno, José Perea Martins [197?, p. 11] assim se refere a essa palavra6 "[...] verdadeira palavra mágica da nossa língua". A palavra que é um pronome substantivo relativo (com referência ao gênero neutro). Vem da forma quod (acusativo singular, tido como o caso lexicogênico). No Latim clássico e da decadência, "possuiu, além das formas substantivo relativo e conjunção, outras que, salvo exceções, equivaliam a: quais = pronomes interrogativos; quam = advérbios; quod e quia = conjunções" (MARTINS, [197?], p. 15-16). Também Bluteau (1728, p. 32) observa: "Naõ he fácil reduzir a regras certas todos os modos de exprimir em Latim o Que Portuguez".

Martins [197?] afirma não ser uma tarefa fácil verificar as possibilidades de combinação sintagmática de que na Língua Portuguesa:

Dum ponto ao outro, da sua nascença até sua forma atual, impossível seria descrever-se as formas pelas quais passou a palavra - que - em relação aos seus valores diversos, ricamente progressistas, até chegar à forma atual (MARTINS, [197?], p. 15-16).

Apesar disso, traz à discussão algumas expressões as quais ele denomina "interessantes". Consideramos necessário destacá-las:

Fazer com que, com que então, não há de que, que é de?, é que, pois que, que tal, é outro que tal, qual o que!, só que!, que nem, de maneira que, eis que, até que, como que, quem quer que, como quer que seja, onde quer que, em que pese a, dar que falar, que também, do que (MARTINS, [197?], p. 17-25).

No parecer de Said Ali (1964, p. 104), a partícula que, combinada com certos advérbios e alguns particípios perde seu valor primitivo para dar origem a conjunções de nova espécie. Tais são as temporais antes que, depois que, sempre que, as causais visto que, já que, as concessivas ainda que, posto que, dado que etc.

Neves (1997) menciona a existência de palavras funcionais originadas em palavras de conteúdo lexical e que constituem o que se poderia considerar "instâncias prototípicas da Gramaticalização", e cita visto que, uma vez que, posto que, se bem que, a não ser que, de modo que, de maneira que, de forma que e de sorte que, como referências. Segundo a linguista, ocorreria, em expressões como essas, uma diminuição

\footnotetext{
${ }^{6}$ Embora assuma a dificuldade de apreender as propriedades do que na língua, Martins [197?] publica As 27 funções da palavra Que. Grosso modo, são: substantivo, preposição, advérbio, pronome, sujeito, objeto, predicativo, complemento nominal, adjunto adverbial, adjetivo, conjunção, interjeição e partícula expletiva.
} 
v. 7 (1)

$57-75$

jan/jun

2017

do estatuto categorial de itens gramaticalizados, e consequente o aparecimento de formas híbridas. Nesse caso, "as formas tendem a perder ou neutralizar os marcadores morfológicos e as características sintáticas próprias das categorias plenas" (NEVES, 1997, p. 120).

Em Bechara (2010), há inúmeros casos de locuções nas quais advérbios se unem ao transpositor relativo que e, com isso, têm o significado original alterado. São exemplos o já (temporal) e o ainda (também temporal), que assumem um papel diverso em locuções que formam orações subordinativas, como já que (causal ou condicional) e ainda que (concessiva).

A ideia de puro realce da partícula que surge em algumas locuções conjuntivas, em que Bechara (2010) considera o que excessivo e cita exemplos nos quais que se une a advérbios: enquanto que, apenas que, embora que, mal que. Bechara (2010, p. 331) afirma que construções como essas são condenadas por puristas da língua, visto que os advérbios, "só por si funcionam como adjuntos adverbiais".

Sobre "palavras expletivas" ou "de realce", Said Ali (1951, p. 48) opina:

Figuram muitas vêzes no falar corrente, e em particular nos diálogos, palavras e frases que parecem de sobra nas proposições quando estas se analisam com os recursos usuais da gramática e da lógica. Todo o mundo as emprega espontaneamente, mas não a êsmo, e sim em determinadas condições.

As locuções citadas por Said Ali (1964), Neves (1997) e Bechara (2010) alocam-se no conjunto das orações subordinadas e, portanto, estão afiançadas pela gramatical tradicional. Das citadas por Martins [197?], a maioria é licenciada pelo sistema da Língua Portuguesa. De um modo ou de outro, unir palavras à partícula que indica ser, como vimos, um processo de domínio geral da língua e, partilhando da opinião de Said Ali (1951), concluímos que as relações estabelecidas entre que e algumas unidades da língua "[...] não são desnecessárias. Basta tentar eliminá-las, para ver que as proposições se tornam mais vagas e falhas de certo intuito que temos em mente" (SAID ALI, 1951, p. 48) [grifo nosso].

Nessa direção, foi com o objetivo de delinear rotas de gramaticalização no português e identificar usos inovadores que o Grupo de Pesquisa sobre Mudança Gramatical do Português, da Universidade de São Paulo (USP), coordenado pela professora e pesquisadora Dra. Maria Célia Lima-Hernandes, criou, em 2006, o Projeto Rotas de gramaticalização no Português do Brasil: estruturas X-que no Português Culto. Consoante à pesquisa, identificou 
alguns exemplos do fenômeno $\mathrm{X}$-que são as estruturas derivadas de verbos volitivos e estruturas inovadoras de caráter adverbial. Essas estruturas constituem cadeias sintáticas com valores ambíguos e são, algumas vezes, interpretadas como erros por professores. Há, entretanto, uma motivação discursivo-pragmática para a emergência desses usos e a combinação dos princípios propostos por Castilho (2004) associada a um método de controle frequencial híbrido constitui-se o caminho adequado para a descrição satisfatória dos deslizamentos funcionais, para a identificação dos gatilhos discursivo-pragmáticos e para o delineamento das rotas de gramaticalização de estruturas X-que no português?

Desse projeto, surgiram estudos para tratar da gramaticalização de advérbios (sempre + que), (ainda + que), [meio + que $]$ e (quase + que), de deslizamentos funcionais de verbos [verbo $+q u e]$, como [tirar $+q u e]$ e [acabar + que].

$\mathrm{Na}$ atualidade, é grande a quantidade de exemplos em que essa palavra se associa a outras para compor novas estruturas, com advérbios $[$ meio + que $]$, preposições [fora +que] e os verbos [ter + que], [acaba + que], [tirando +que], [ $\mathrm{vai}+q \mathrm{qu}]$, para citar alguns. Vai que aparece em Vai que dá certo (Imagem Filmes, 2013) e Vai que cola (H2O, 2015), títulos de filmes brasileiros, e também na linguagem jornalística. Não faz muito tempo, ouvimos de uma repórter: Vai que a empresa abre uma vaguinha (Michele Loreto, Jornal Hoje, em 07 de setembro de 2015). Recentemente, o "só que", introdutor de construção adversativa, adquiriu um efeito cômico/irônico na expressão coloquial, "Só que não".

Todas essas evidências mostram a especialidade do falante em, diante da língua, unir palavras à partícula que por meio de encadeamento. Isso faz surgir fenômenos como [meio + que], uma estrutura que intitula livro (14), aparece em letra de música (15), manchete de blog (16), site de fofoca (17), inclusive no discurso de jornalistas renomados (18) e (19) em programas que visam alcançar o grande público e cuja linguagem se caracteriza pela falta de formalidade:

(14) "Ficando longe do fato de já estar meio que longe de tudo", título do livro de David Foster Wallace (tradução, Companhia das Letras);

(15) Percebeu que eu tava a fim ela sentiu no ar. E deu meio que um sorriso pra me provocar (Um minuto Exaltasamba);

\footnotetext{
${ }^{7}$ Disponível em: < http://dlcv.fflch.usp.br/node/96/>. Acesso em: 08 ago. 2017.
} 
v. 7 (1)

57-75

jan/jun

2017

(16) Agripino e Rosalba: Conversa "meio que assim..." (Blog Serrinha de Fato, setembro de 2013);

(17) "Fiuk recebe presente meio que inusitado de sua mãe" (http://tvfoco.pop.com.br);

(18) "É a sensação de que você meio que cumpriu sua missão" (Fátima Bernardes, Programa Encontros, Rede Globo, out. 2013).

(19) "[...] se a gente faz reportagem mostrando o problema que, seja do que for, da calçada, seja qual for, a gente percebe que, assim, todo mundo meio que já sabe isso [...]" (Rodrigo Bocardi, Programa Mais Você, Rede Globo, agosto de 2013).

Temos, portanto, o processamento em conjunto da estrutura [meio + que], em que dois elementos de funções gramaticais, categorias sintáticas e domínios cognitivos distintos se encadeiam e passam a compor uma locução, uma única expressão que, "apesar de explícita, não se denota sua mescla" (SPAZIANI, 2008, p. 27). Cuidaremos dessa relação, que será melhor discorrida na próxima seção.

\section{A locução [meio + que]: encadeamento e propriedades}

Não existe uma teoria que dê conta da fórmula [meio + que], a qual ocorre repetidas vezes entre os falantes mais jovens do Corpus PCVC. Desse modo, não é tão fácil fazer uma análise morfossintáticosemântica dessa construção. Por ora, fica definido que se trata de uma "locução". Vamos explicar por quê.

Bueno (1974, p. 686) define locução de duas maneiras. A primeira, "reunião de palavras que equivale a uma só", diz respeito ao encadeamento. A segunda, "maneira especial de falar". São sete espécies de locução: adjetiva, adverbial, interjeicional, nominal, pronominal, verbal e conjuntiva. A princípio, acreditamos na possibilidade de esta última ser a que mais se aproximasse do nosso objeto de estudo, por tratar de orações transpostas pela conjunção que (BUENO, 1974, p. 686).

Ao contrário do que imaginamos, [meio + que] não tem a função de locução conjuntiva, visto não conectar sentenças, mas funciona como articulador textual em contexto de modalização. Tomemos os fragmentos:

(20) [... a cidade ela fica meio que dentro de um... dentro de um buraco assim...] (L.M.R.J., PCVC, I, M) 
(21) [... ela é meio que assim um equilibriozinho, sabe? entre o pai e a mãe...] (C.B.S., PCVC, I, F)

Acima, dois contextos. Em (20), uma cidade com uma localização desfavorável. Em (21), uma irmã que proporciona segurança à família. Ambas as afirmativas são feitas com reservas, com uma significação atenuada por meio do recurso [meio + que].

Analisado em Nogueira (2014, p. 13), sob a designação "avaliação com certo grau de imprecisão", meio que teria um valor discursivopragmático associado à categoria cognitiva de qualidade e "funcionaria como um evidencial na situação comunicativa" (p. 13).

Como atenuador da informação, [meio + que] desempenha uma função inversa à das orações clivadas em português. As clivadas8 são formadas com o auxílio do verbo ser mais um relativo, que ou quem (PERINI, 2010, p. 333), em contextos nos quais se quer enfatizar um constituinte.

De outra forma, temos, na Língua Portuguesa, a fórmula [mais + que]. Anteposta a adjetivo, ela reforça o sentido da expressão à qual se refere, e equivale a "excessivamente", "em demasia" (SAID ALI, 1964, p. 104). Assim, se dispomos de construções como "Um cometimento mais que ousado" ou "A dívida está mais que paga" (SAID ALI, 1964, p. 104), em que a expressão [mais + que] evoca força, vigor, abundância, por analogia, podemos ter atenuada a franqueza de certas afirmações com $[$ meio + que $]$ :

(22) [... aí parto mais mesmo pra o pop rock e tal que ainda é algo meio que preservado...] (C.B.S.)

(23) Então, foi meio que induzida a entrar nesse caminho (L.C.S.)

Na estrutura a que ora nos referimos, o padrão é [meio + que], porque a "intenção do falante mantém-se em grande parte dentro do que é permitido pela língua ou pela tradição linguística" (COSERIU, 1979, p. 69), de forma que podemos até encontrar "pouco que preservado", "pouco que induzida", mas, talvez não, "muito que preservado", "muito que induzida" ou, ainda, "menos que preservado", "menos que induzida".

\footnotetext{
${ }^{8}$ As construções "Maria quem fez o bolo" e "A cor é que não agradou muito", por exemplo, têm por objetivo dar um destaque aos termos "Maria" e "cor". As frases simples seriam "Maria fez o bolo" e "A cor não agradou muito".
} 
v. 7 (1)

$57-75$

jan/jun

2017

Ademais, na construção meio que, soaria estranho dizer "mais qual", "meio qual". Também não observamos ocorrências substantivadas "o meio que", nem flexionadas "meia que", embora alguns contextos favorecessem a variabilidade:

(24) ... foi [meio] que [induzida] a entrar nesse caminho, mas, é... foi uma... (L.C.S.)

(25) ... [ela] é [meio] que assim um equilibriozinho, sabe? entre o pai e a mãe... (C.B.S.)

(26) ... [uma transição] [meio] que chocante (C.S.M.N.)

O sistema funcional do PCVC oferece diversas possibilidades com a fórmula [meio + que]. Boa parte ocorre em contextos, nos quais os informantes avaliam situações que suscitam divergências e, por meio da locução [meio + que], tentam-se desvincular do que sustentaram e do compromisso com adjetivos de sentido robusto, como "fútil" aplicado à realização da Copa do Mundo no Brasil, em (27), "preservado" o pop rock em relação às músicas atuais, em (28), e "polêmico" o trabalho infantil, em (29).

(27) [...] eu acho meio que [fútil] [isso]. (L.C.S.)

(28) [...] é [algo] meio que [preservado] (C.B.S.)

(29) [...] tem... [um... aspecto] meio que [polêmico], alguns falam que criança não devem trabalhar (C.S.M.N.).

Nessas três ocorrências, do ponto de vista semântico, que e meio se unem e formam uma locução capaz de fazer com que os adjetivos em questão tomem seu valor mínimo e desvinculem o informante do compromisso com o que afirmaram. Na perspectiva da gramática normativa, trata-se de contextos predicativos em que o relativo que se junta a meio, sem lhe ser essencial, de modo que é possível "meio fútil", "meio preservado" e "meio polêmico". Se, nesses casos, o que poderia figurar como acessório, nos enunciados a seguir, essa partícula se une a meio e aparece depois de sujeito como o mais importante termo para delimitar o sentido de verbos em orações declarativas:

(30) a gente [meio que] esbarrou ali (L.C.S.)

(31) o velhinho ele [meio que]... ele dorme e... morre (L.M.R.J.)

(32) eu [meio que] me interessei pela música (L.C.S.)

(33) você [meio que] tem sua autonomia (L.M.R.J.) 
A fórmula [meio + que] surge também depois de tipos variados de verbos, constituindo argumentos de predicados, de modo que não pode faltar na sentença por ser parte integrante do sentido que se tem dela:

(34) ele [vai] meio que relatano assim (L.M.R.J.)

(35) ele [tenta] meio que dá um direcionamento pro... (L.M.R.J.)

Pode, inclusive, servir de recurso expressivo, altamente significativo, para modificar orações, as quais não admitem a possibilidade de negação nem de interrogação.

(36) [meio que] eu criei um pouco cada um. (L.C.S.)

(37) [meio que] lhe tratam como adulto (L.M.R.J.)

Menos corrente, [meio + que] aparece ao lado de um relativo (38) ou, às vezes, substituindo esse pronome (39):

(38) Mas é uma certa brincadeira que [meio que] a criança fica ali isolada no seu mundo (L.C.S.)

(39) foi numa época [meio que]... eu 'tava descobrindo a leitura. (L.C.S.)

Ou, ainda, reforçado por outro elemento modalizador:

(40) Aí eu fui deixando essa data [meio] [assim] [que] de lado (L.C.S.)

Em (40), o informante lança mão também do assim. Coseriu (1979, p. 69) afirma que "para corresponder à sua necessidade expressiva, o falante pode recorrer a modos e elementos de outros sistemas". No entorno do [meio + que], o assim é o termo mais recorrente, seguido de certa, uma coisa e outras estruturas, todas de sentido vago e impreciso. Foi o que identificamos nos trechos:

(41) [...] ela é [meio que] [assim] um equilibriozinho, sabe? entre o pai e a mãe...[...] (C.B.S.)

(42) [...] é uma [certa] brincadeira, que [meio que] a criança fica ali isolada no seu mundo (L.C.S.) 
v. 7 (1)

$57-75$

jan/jun

2017

(43) [...] essa professora ela tinha [meio que] [uma coisa] comigo, não sei... não posso dizer agora a palavra correta (L.C.S.)

(44) Esse livro pra mim, foi [numa época] [meio que]... eu 'tava descobrindo a leitura. (L.C.S.)

(45) [...] como eu vou dizer elas [meio que]... [sei lá]... é como se $[\ldots]$ (C.B.S.)

(46) [...] parto mais mesmo pra o pop rock e tal que ainda é [algo] [meio que] preservado (C.B.S.).

Em algumas ocorrências, essa expressividade interrompe o encadeamento, como acontece em (47). Em outras, a alternância [meio + que], um pouco pode indicar hesitação (48):

(47) Aí eu fui deixando [essa data] [meio [assim] que] de lado, mas nada contra. (L.C.S.)

(48) e eu sou a mais velha de todos, então, [meio que]... eu criei [um pouco] cada um. (L.C.S.)

Nas orações, [meio + que] assume, ora o sentido de "um tanto", um pouco, "em parte" (49) e (50), ora o de "quase" (51) e (52), sempre estabelecendo uma relação aproximada, porém, de imprecisão, sempre desobrigando o falante do compromisso com o conteúdo do enunciado:

(49) se essas pessoas tá tendo essa atitude então é [meio que] controverso cobrar uma atitude justa dos governantes, (C.S.M.N.)

(50) um... aspecto [meio que] polêmico, alguns falam que criança não deve trabalhar (C.S.M.N.)

(51) Então, foi [meio que], induzida a entrar nesse caminho, mas, é... foi uma... (L.C.S.)

(52) [...] a gente [mei que] se entregou ali, um ao outro (L.C.S.).

Esse mesmo sentimento de incerteza que permeia a locução ora analisada aparece nos vocábulos meio e que isolados. Abonado por citações de clássicos como Cícero, Bluteau (1728) refere-se à falta de precisão da partícula que: 
Hum naõ jey que. Aquelle naõ sey que. São modos de falar, quando naõ podemos, ou naõ queremos exprefJar claramente algũa couja. Sinto naõ jey que, Sentio nejcio quid. Cicero diz Nejcio quis, Hum naõ jey quem (BLUTEAU, 1728, p. 32).

Sobre o uso de meio, Said Ali (1964), afirma: quando há em um ser duas qualidades, atributos, ou condições que se contradizem, e o falante quer "significar a incerteza de nosso juízo, antepondo a cada um dos dous adjetivos (ou substantivos que fazem as vezes de adjetivo) a palavra meio" (p. 301).

Com essas evidências, podemos afirmar: as propriedades dessas duas palavras na locução [meio + que] indicam um deslocamento de sentido, um estágio avançado de gramaticalização, tal como prevê o referencial teórico funcionalista. A transferência de sentidos, pela metáfora, pela analogia com antigos usos, e também do ponto de vista semântico, ocasionou uma maneira especial de falar. A nova estrutura, do ponto de vista sintático, pela metonímia, originou a disposição harmoniosa de dois elementos em informações que não sinalizam uma ação concreta e precisa, mas uma hesitação, uma imprecisão, um valor aproximativo.

\section{Considerações finais}

Neste estudo, analisamos, no Corpus de fala dos informantes do PCVC, a locução [meio + que], formada por dois elementos que desempenham funções gramaticais diversas, mas que empreendem um deslizamento funcional com amparo nos princípios Funcionalistas, no processo de gramaticalização e indica a dinamicidade da gramática, em consequência da incessante criação de expressões e de arranjos na ordenação vocabular. Trata-se de um mecanismo recorrente que reflete um processo de incorporação de novos constituintes à língua para estender os sentidos de palavras. No caso deste estudo, [meio + que] é um recurso expressivo para atenuar o significado de determinadas expressões.

O estudo mostra que, apesar de dispor de meio, mas, estabelecendo, do ponto de vista da metáfora, uma analogia com usos mais antigos em outras construções da língua, cujos processos de mudanças já ocorreram, o falante cria [meio + que]. Do ponto de vista da metonímia, temos uma mudança na sintaxe com a junção dessas duas palavras. Muitos estudiosos não consideram essa locução. Se, do ponto 
v. $7(1)$

57-75

jan/jun

2017

de vista formal, ela pode ser considerada, sem motivos, erro, do ponto de vista funcional, essas duas palavras se unem sequencialmente para compor um todo na sentença e assumir uma nova posição na escala de valores expressivos, julgados necessários pelo interlocutor no ato de comunicação.

A locução [meio + que] ganha propriedades morfológicas, sintáticas e semânticas e desempenha um papel importante no discurso, visto que é portadora da ideia ou do sentimento de incerteza. O falante consegue, portanto, transcender a finalidade de ser mais expressivo e amplia, ao máximo, a aparente necessidade de quebra de clareza do pensamento.

\section{Referências}

BECHARA, Evanildo. Gramática escolar da Língua Portuguesa. 2. ed. Rio de Janeiro: Nova Fronteira, 2010.

BYBEE, J. Language, usage and cognition. Cambridge, UK: CUP, 2010.

BLUTEAU, Raphael. Vocabulario portuguez \& latino: aulico, anatomico, architectonico. Coimbra: Collegio das Artes da Companhia de Jesus, 1712 -1728. 8 v. Versão digital disponível em: <http://www.brasiliana.usp.br/en/ dicionario/2/meio>. Acesso em: set. 2015.

BUENO, Francisco da Silveira. Grande dicionário etimológico-prosódico da língua portuguesa. São Paulo: Brasília Limitada, 1974. 5 v.

CASTILHO, Ataliba T. de. A gramaticalização. Cadernos de Estudos Linguísticos e Literários, Salvador: UFBA, n. 19, p. 25-60, 1997.

CASTILHO, Ataliba T. de. Nova gramática do português brasileiro. São Paulo: Contexto, 2012.

COSERIU, Eugenio. Sincronia, diacronia e história: o problema da mudança linguística. Tradução de Carlos Alberto da Fonseca e Mário Ferreira. São Paulo: Presença, 1979.

CUNHA, Maria Angélica Furtado da; BISPO, Edvaldo Balduino; SILVA, José Romerito. Linguística funcional centrada no uso: conceitos básicos e categorias analíticas. In: CEZARIO, Maria Maura; CUNHA, Maria Angélica Furtado da. Linguística centrada no uso: uma homenagem a Mário Martelotta. Rio de Janeiro: Mauad X; FAPERJ, 2013.

FERREIRA, Aurélio Buarque de Holanda. Novo Dicionário Aurélio da Língua Portuguesa. 4. ed. Curitiba: Positivo, 2009.

GONÇALVES, Sebastião Carlos Leite; HERNANDES, Maria Célia; CASSEBGALVÂO, Vânia Cristina. Tratado geral sobre gramaticalização. In:

Introdução à gramaticalização. Sã̃o Paulo: Parábola Editorial, 2007. 
HEINE, B.; CLAUDI, U.; HÜNNEMEYER, F. Grammaticalization. A Conceptual Framework. Chicago: The University of Chicago, 1991.

JUCÁ FILHO, Cândido. Dicionário escolar das dificuldades da Língua Portuguesa. Brasília: MEC, 1963.

LIMA, Gilsileide Cristina Barros. De meyo a meio que: usos e gramaticalização do item linguístico meio no vernáculo conquistense. 2016. $101 \mathrm{f}$. Dissertação (Mestrado em Linguística) - Universidade Estadual do Sudoeste da Bahia, Vitória da Conquista, Bahia, 2016.

LIMA-HERNANDES, Maria Célia. A evolução da gramática e o aporte funcionalista: bases teóricas. In: Indivíduo, sociedade e língua: cara, tipo assim, fala sério! São Paulo: Edusp, 2011. p. 21-53.

MARTELOTTA, Mário Eduardo (Org.). Linguística funcional: teoria e prática. Rio de Janeiro: DP\&A Editora, 2003.

MARTINS, José P. As 27 funções da palavra Que. Rio de Janeiro: TecnoprintEdiouro, [197?].

NEVES, Maria Helena de Moura. A gramática funcional. São Paulo: Martins Fontes, 1997.

NOGUEIRA, Priscilla de A. Gramaticalização da construção quase que: motivações cognitivas para o uso da construção e incerteza. 2014. 298 f. Dissertação (Mestrado em Filologia e Língua Portuguesa) - Universidade de São Paulo, São Paulo, 2014.

PERINI, Mário A. Gramática do português brasileiro. São Paulo: Parábola, 2010.

SAID ALI, M. Gramática Secundária da Língua Portuguesa. 3. ed. Brasília: Editora da Universidade de Brasília, 1964.

SAID ALI, M. Meios de expressão e alterações semânticas. 2. ed. Rio de Janeiro: Organização Simões, 1951. (Coleção "Rex").

SILVA, Antonio Moraes. Diccionario da lingua portugueza - recompilado dos vocabulários impressos ate agora, e nesta segunda edição novamente emendado e muito acrescentado, por ANTONIO DE MORAES SILVA. Lisboa: Typographia Lacerdina, 1789. Versão digital disponível em: <http://www. brasiliana.usp.br/en/dicionario/2/meio>.

SPAZIANI, Lídia. A gramaticalização do item fora no Português do Brasil: a unidirecionalidade do processo. 2008. 137 f. Dissertação (Mestrado em Filologia e Língua Portuguesa) - Universidade de São Paulo, São Paulo, 2008.

Recebido em: 15 de fev. de 2017.

Aceito em: 24 de ago. de 2017. 